\title{
Final year medical students' understanding of family medicine
}

\author{
Marija Petek Šter ${ }^{1}$, Igor Švab ${ }^{1}$, Branko Šter ${ }^{2}$ \\ ${ }^{1}$ Department of Family Medicine \\ Medical Faculty, University of Ljubljana \\ Ljubljana, Slovenia \\ ${ }^{2}$ Faculty of Computer and Information \\ Science, University of Ljubljana \\ Ljubljana, Slovenia \\ Corresponding author: \\ Marija Petek Šter \\ Department of family medicine \\ Medical faculty \\ University of Ljubljana \\ Poljanski nasip 58 \\ 1000 Ljubljana \\ Slovenia \\ marija.petek-ster@mf.uni-lj.si \\ Tel.: + 38614386915 \\ Fax.: + 38614386910 \\ Received: 19 June 2013 \\ Accepted: 29 November 2013 \\ Copyright (C) 2014 by \\ Academy of Sciences and Arts \\ Objective. The European Academy of Teachers in General Practice \\ / Family Medicine (EURACT) has developed an educational agenda, \\ the key document for teaching family medicine in Europe. The aim of \\ our study was to find out how final year medical students at the begin- \\ ning of their family medicine clerkship understand the discipline of \\ family medicine. Methods. The attitudes toward family medicine were \\ paraphrased and developed into a 164-item questionnaire, which was \\ administered to 335 final-year medical students at the beginning of \\ their clerkship. Using combinatorial optimization with genetic algo- \\ rithms we selected 30 items which yielded the highest Cronbach alpha \\ reliability coefficient. Finally, we performed a factor analysis to find \\ which dimensions of family medicine were recognised by the students \\ and compared them with the domains defined in the EURACT defini- \\ tion. Results. The 30-item questionnaire had a Cronbach alpha reli- \\ ability coefficient of 0.919 . The differences between male and female \\ students were not very significant $(\mathrm{p}=0.061)$. With the factor analysis \\ we recognised seven factors, belonging to three out of six domains of \\ the EURACT educational agenda: primary care management, person- \\ centeredness and comprehensive approach. Conclusion. Final-year \\ medical students at the beginning of their family medicine clerkship \\ understand some of the dimensions of family medicine rather well, \\ but they are not aware of some important competences of family doc- \\ tors. There is a necessity to teach students about specific problem solv- \\ ing skills and the importance of balance between the health needs of \\ an individual patient and the community.
}

of Bosnia and Herzegovina.

E-mail for permission to publish:

amabih@anubih.ba
Key words: Family medicine, Medical students, Understanding of family medicine, EURACT Educational agenda.

\section{Introduction}

In the majority of European countries, general practice / family medicine (GP/FM) is a fundamental part of the health care system. General practice / family medicine is a professional and scientific discipline with its own definition and competences. The key document which explains the discipline is European Definition of Family Medicine
(1). GP/FM is now taught in most medical schools in Europe and vocational training is mandatory in most countries; in some of them new programmes for vocational training have been recently introduced (2).

An FM clerkship can allow students to understand the importance of primary care and of the significance of the general practitioner's role in the healthcare system, and 
may also influence their career choice (3). After classes in FM, students report an improvement of their knowledge and attitudes towards FM, they form a positive perception of primary care practice and may also change their perception about the professional demands of primary care physicians (4).

To fulfil the aims of FM teaching, the Academy of Teachers in Family Medicine (EURACT) developed the Educational Agenda, the key document on FM teaching in Europe (5). The agenda is written as an explanation of the core competences of FM. It also includes a template with a list of broader objectives, teaching methods and assessment tools for each of the competences.

There are some reports that the competences defined in the Educational Agenda are not understandable to medical students or to experienced general practitioners (6, $7)$. Students usually understand the clinical competences of family doctors (8), but fail to understand other competences of family doctors, such as long term care and patient centeredness $(9,10)$, community orientation (7) and medical leadership and management (11).

As teachers, we would like to know how our student at the beginning of our rotation understands the discipline and to adapt our teaching if the student's understanding of the discipline is not sufficient. The aim of our teaching is for students to know and value the broad spectrum of competences which are typical for FM.

Based on our previous analysis (12) we decided to enlarge the sample of students participating in the research and to try to analyse the statements in the questionnaire as a whole (not divided into competences according to the definition) by using a genetic algorithm based combinatorial optimization, and later, by factor analysis, to find out which dimensions of FM were recognised by the students. Genetic algorithms have already been used in medicine, mainly for image segmentation tasks, but also for feature selection and model optimization $(13,14,15)$.

\section{Methods}

All final-year ( $6^{\text {th }}$ year) students at the Medical Faculty in Ljubljana, who were at the beginning of their family medicine clerkship, were invited. Nobody refused participation. The questionnaire was distributed to 335 students; 112 (33.4\%) male and 223 (66.6\%) female students. 14 questionnaires (4.2\%) were excluded from the analysis due to incomplete data. 321 questionnaires were included in further analysis. The questionnaires were distributed by teachers at the beginning of the family medicine clerkship.

\section{Development of the draft questionnaire}

The questionnaire about attitudes was developed specifically for the purpose of the study. In the first stage, the European definition of FM was distributed to a group of 30 experienced family physicians (teachers of $\mathrm{FM}$, involved in the teaching process at the undergraduate level). They were asked to use their imagination in developing statements that would reflect attitudes about each of the core competences listed in the Educational Agenda (5).

The statements were collected and paraphrased by one of the researchers (MPS) and organized into a list of statements that could be used in a questionnaire. This draft questionnaire was then sent to the same group of teachers for comments. After the comments were received, two researchers (IS, MPS) independently assessed them. The formulation of the draft questionnaire was the result of a consensus meeting between the two researchers. There was no need for a third expert to sort out potential conflicts. The result of this process was a list of 164 statements. 
A seven-point Likert scale measures agreement. A score of 1 means total disagreement and a score of 7 means total agreement. The draft questionnaire consisted of 164 statements based on the Educational Agenda. In order to ensure maximum confidentiality and anonymity, no social or demographical data except gender was collected. A detailed explanation of the development and validation of the draft questionnaire has already been published (12).

\section{Selection of items for the final questionnaire using a genetic algorithm}

To find the subset of questionnaire items with the largest possible Cronbach alpha coefficient, a search procedure called "combinatorial optimization" must be applied. One of the best combinatorial optimization methods is the genetic algorithm (GA) (16, 17,18 ).

GA, which belongs to the larger class of evolutionary algorithms (EAs), is a robust optimization algorithm that mimics the natural evolution process. It uses evolutionary operators, such as inheritance, selection, mutation and crossover. In EAs, a problem may be viewed as an environment, and feasible solutions may be viewed as individuals living in this environment. Similar to natural evolution, where the fittest individuals generally tend to survive, the best solutions in an EA also tend to survive, create offspring and mutate in order to produce even better solutions.

Each potential solution may be viewed as a chromosome or genotype. It is usually a string, composed either of bits or real numbers. A population of chromosomes encode candidate solutions to an optimization task. The initial population consists of randomly generated chromosomes. Using evolutionary operators of selection, mutation and crossover, the next generations of the population are produced. On average, each sub- sequent generation consists of better chromosomes or solutions for the task. We are usually interested in the best chromosome that appears during the course of the algorithm, being the best solution so far.

For a GA an evaluation or fitness function must always be provided. It measures the quality of each chromosome, as a candidate solution to the specified problem. This is the only strictly problem-specific part of the genetic algorithm. The others may be more or less generic.

In our case, a chromosome encodes which items are present in the itemset. Since we are looking for the best of all the itemsets of a particular size, a fixed number of bits has the value of 1 . In this case it is not possible to mutate bits in a random manner, since the number of items may change. What we need is a mutation that performs only permutations on the chromosome. With some small probability (mutation probability) a randomly selected 1 is replaced by a randomly selected 0 . Therefore, an item is replaced by some other item. The crossover operation is more tricky and will not be described here.

Our goal was to find a subset of the questionnaire items that would yield the highest possible Cronbach alpha coefficient. On the other hand, it is known that larger subsets yield larger alpha values. As a reasonable size for the questionnaire (the number of items) we chose 30 .

The size of the search space (the number of all possibilities) is huge. It amounts to

$$
\left(\begin{array}{c}
164 \\
30
\end{array}\right) \approx 7 \cdot 10^{32},
$$

which is the number of different 30 -item subsets out of a 164 -item set. It is obvious that no method is guaranteed to produce the optimal solution. However, the GA usually finds near-optimal solutions. The value of the alpha of a candidate subset serves as the evaluation function of the corresponding chromosome. 


\section{Basic data analysis}

We used descriptive statistics: mean values of Likert scale values with standard deviation (SD) for the description of item values and independent sample t-test (two-sided) to compare the total score of the questionnaire between male and female students. We considered a $\mathrm{p}$ value less than or equal to 0.05 to be significant.

\section{Factor analysis}

A principal component factor analysis with varimax rotation was performed to condense the attitudinal items that predict career choice in family medicine into a smaller number of coherent factors. Items that showed a minimum factor loading of 0.5 and factors with eigenvalue greater than 1 were retained.

Two independent researchers (MPS and IS) explained the meaning of the factors. The final explanation of the factors was the result of a consensus meeting between the two researchers, who had discussed the comments and made the final description of the fac- tors. There was no need for a third expert to sort out a potential conflict.

\section{Ethical approval}

The study was presented to the national ethical committee and was given its approval.

\section{Results}

\section{Description of the sample}

We analysed the questionnaires of 321 final year medical students, 109 (34\%) male and $212(66 \%)$ female, at the beginning of their family medicine clerkship.

\section{Description of the 30-item questionnaire}

The genetic algorithm was run for 1000 generations, with 500 chromosomes in the population. Using the genetic algorithm we found the best (or near best) 30-item questionnaire, regarding Cronbach alpha. The reliability of the questionnaire, assessed by Cronbach alpha was 0.919 . The resulting items are presented in Table 1.

Table 1 The 30-item questionnaire

\begin{tabular}{llll}
\hline Item & Range & Mean & SD \\
\hline Physicians should not transfer their professional responsibilities to others & $1-7$ & 6.08 & 1.09 \\
High quality of primary care can save a lot of money & $1-7$ & 6.29 & 1.16 \\
Without patients' cooperation, there is no success in treatment & $1-7$ & 6.44 & 1.01 \\
Without good communication, one cannot work well in practice & $1-7$ & 6.42 & 0.87 \\
A long term doctor-patient relationship improves the efficacy of work & $1-7$ & 5.89 & 1.07 \\
There is no appropriate treatment without trust & $1-7$ & 6.17 & 1.09 \\
The doctor should be objective & $1-7$ & 6.17 & 1.02 \\
A good doctor listens to his patients & $1-7$ & 6.03 & 1.35 \\
A good doctor empathises with the patient in distress & $1-7$ & 5.31 & 1.26 \\
Detailed clarification of a patient's health care problems is important & $1-7$ & 6.06 & 1.10 \\
Priorities of physicians may be different from priorities of patients & $1-7$ & 5.93 & 1.21 \\
Treatment plan should be adapted to the patient & $1-7$ & 6.28 & 0.91 \\
Priorities of patients' care may change & $1-7$ & 5.71 & 1.29 \\
The patient's personality should be taken into account in treatment & $1-7$ & 5.63 & 1.28
\end{tabular}


Table 1 (continued)

\begin{tabular}{llll}
\hline Item & Range & Mean & SD \\
\hline The psychological dimension of the disease is usually as important as the physical aspect & $1-7$ & 6.27 & 0.99 \\
Advice for a healthier lifestyle is an important duty of the physician & $1-7$ & 6.38 & 1.06 \\
Physicians educate by their own example & $1-7$ & 5.74 & 1.48 \\
Palliative care is as important as active treatment & $1-7$ & 6.15 & 1.35 \\
Prevention is a key to good health & $1-7$ & 5.76 & 1.38 \\
For each patient one should include preventive advice & $1-7$ & 5.68 & 1.44 \\
At each visit, one should include preventive advice & $1-7$ & 5.65 & 1.61 \\
It is important that the doctor knows the legal limitations of his work & $1-7$ & 6.05 & 1.23 \\
All patients should have the same level of care regardless of their social status & $1-7$ & 6.12 & 1.50 \\
Physicians should adapt their working style to the needs and possibilities of the community where & $1-7$ & 5.58 & 1.16 \\
they work & $1-7$ & 6.55 & 0.88 \\
Under given circumstances, physicians should provide the same level of care to all patients & $1-7$ & 5.76 & 1.29 \\
Physicians should cooperate with the local community & $2-7$ & 5.79 & 1.14 \\
Computerization helps to achieve a high quality of work & $1-7$ & 5.89 & 1.21 \\
Physicians should know the legal framework of the health care system & $1-7$ & 6.14 & 1.40 \\
Patients should know their rights and also their duties & $1-7$ & 6.14 & 1.13 \\
If necessary, the family should be included in the treatment &
\end{tabular}

The mean sum of all items was from 41 to 203, with a mean of 173.7 (SD 19.2). The differences between the male and the female students were not significant (t-test, $\mathrm{p}=0.061$ ).

\section{Factor analysis}

Using the component factor analysis with varimax rotation we explained $57.3 \%$ of the total variance. The proportions of the variance explained by the particular factor after varimax rotation (rotation sums of squared loading) is presented in Table 2.

Table 2 The proportions of the explained variance

\begin{tabular}{llll}
\hline Component & Eigenvalue & \% of Variance & Cumulative \% \\
\hline 1 & 4.30 & 14.33 & 14.33 \\
2 & 2.36 & 7.98 & 22.31 \\
3 & 2.34 & 7.81 & 30.13 \\
4 & 2.31 & 7.68 & 37.81 \\
5 & 2.27 & 7.65 & 45.46 \\
6 & 2.14 & 7.15 & 52.61 \\
7 & 1.41 & 4.70 & 57.31 \\
\hline
\end{tabular}

Table 3 presents the items, classified by factor analysis. Items with loading of 0.5 or more and the component to which the item belongs were bolded. Six items had loading of less than 0.5.

Based on the factor analysis, we identified seven factors explaining the students' understanding of FM. The first factor which explains most of the variability is related to prevention and palliative care. The factors are as listed:

1. Prevention/palliative care;

2. Social justice

3. Health care management

4. Person centeredness

5. Partnership/communication

6. Empathy

7. Financial efficacy

Table 4 shows the comparison of the students' understanding of the discipline with the competences of general practice/family medicine defined by the educational agenda. Students recognised three out of six competences quite well. They failed to recognise the competence of specific problem-solving skills, community orientation and the holistic approach. 
Table 3 Rotated component matrix. Factors with loading greater than 0.5 are bolded

\begin{tabular}{|c|c|c|c|c|c|c|c|}
\hline Item & \multicolumn{7}{|c|}{ Component } \\
\hline Prevention is a key to good health & 0.76 & 0.02 & -0.01 & 0.15 & -0.08 & 0.23 & 0.15 \\
\hline For each patient one should include preventive advice & 0.74 & 0.13 & 0.11 & 0.13 & 0.22 & 0.08 & 0.06 \\
\hline At each visit, one should include preventive advice & 0.70 & 0.29 & 0.06 & 0.08 & 0.15 & 0.17 & -0.06 \\
\hline Physicians educate by their own example & 0.60 & 0.20 & -0.01 & 0.29 & 0.20 & -0.08 & -0.14 \\
\hline Patients should know their rights and also their duties & 0.59 & 0.16 & 0.36 & 0.06 & 0.15 & 0.09 & 0.10 \\
\hline Advice for a healthier lifestyle is an important duty of the physician & 0.51 & 0.38 & 0.13 & 0.06 & 0.26 & 0.26 & 0.24 \\
\hline The doctor should be objective & -0.06 & 0.51 & 0.14 & 0.34 & 0.28 & -0.07 & 0.03 \\
\hline It is important that the doctor knows the legal limitations of his work & 0.34 & 0.45 & 0.45 & 0.14 & 0.09 & -0.06 & 0.19 \\
\hline $\begin{array}{l}\text { The psychological dimension of the disease is usually as important as the } \\
\text { physical aspect }\end{array}$ & 0.22 & 0.43 & 0.11 & 0.22 & 0.25 & 0.41 & 0.19 \\
\hline Computerization helps to achieve high quality of work & 0.31 & 0.00 & 0.59 & 0.06 & -0.04 & 0.43 & -0.00 \\
\hline Physicians should know the legal framework of the health care system & 0.47 & 0.05 & 0.61 & 0.09 & 0.15 & 0.03 & 0.26 \\
\hline Physicians should cooperate with the local community & 0.33 & 0.09 & 0.16 & 0.54 & -0.05 & 0.31 & -0.25 \\
\hline Physicians should not transfer their professional responsibilities to others & 0.29 & 0.07 & -0.11 & 0.48 & 0.31 & -0.00 & 0.30 \\
\hline Detailed clarification of patient's health care problems is important & 0.11 & 0.37 & -0.02 & 0.43 & 0.03 & 0.20 & 0.29 \\
\hline Without patients' cooperation, there is no success in treatment & 0.27 & 0.09 & 0.13 & 0.13 & 0.70 & -0.05 & 0.09 \\
\hline Without good communication, one cannot work well in practice & 0.09 & 0.44 & -0.01 & 0.31 & 0.51 & 0.19 & 0.03 \\
\hline There is no appropriate treatment without trust & 0.14 & 0.00 & 0.22 & 0.08 & 0.50 & 0.37 & 0.28 \\
\hline A good doctor listens to his patients & 0.22 & 0.22 & 0.12 & -0.07 & 0.50 & 0.34 & 0.27 \\
\hline If necessary, the family should be included in treatment & 0.17 & 0.24 & 0.43 & 0.08 & 0.47 & 0.23 & -0.29 \\
\hline The patient's personality should be taken into account in treatment & 0.05 & 0.13 & 0.22 & 0.01 & 0.02 & 0.68 & 0.24 \\
\hline A good doctor empathises with the patient in distress & 0.20 & 0.09 & -0.09 & 0.19 & 0.17 & 0.62 & -0.08 \\
\hline A long term doctor-patient relationship improves the efficacy of work & 0.04 & -0.03 & 0.16 & 0.34 & 0.39 & 0.40 & -0.04 \\
\hline High quality of primary care can save money & 0.32 & 0.13 & 0.15 & 0.13 & 0.18 & 0.15 & 0.63 \\
\hline
\end{tabular}


Table 4 Comparison between the competences of FM based on the EURACT Educational agenda and students' understanding of the discipline

\begin{tabular}{ll}
\hline $\begin{array}{l}\text { Competences } \\
\text { based on EURACT } \\
\text { Educational agenda }\end{array}$ & $\begin{array}{l}\text { Competences, recognised by } \\
\text { final year medical students }\end{array}$ \\
\hline $\begin{array}{l}\text { Primary care } \\
\text { management }\end{array}$ & $\begin{array}{l}\text { Social justice (factor 2) } \\
\text { Health care management } \\
\text { (factor 3) } \\
\text { Financial efficacy (factor 7) }\end{array}$ \\
$\begin{array}{l}\text { Person-centered care } \\
\text { Person-centeredness (factor 4) } \\
\text { Partnership / communication } \\
\text { (factor 5) } \\
\text { Empathy (factor 6) }\end{array}$ \\
$\begin{array}{l}\text { Specific problem } \\
\text { solving skills } \\
\begin{array}{l}\text { Comprehensive } \\
\text { approach }\end{array}\end{array}$ \\
$\begin{array}{l}\text { Community } \\
\text { orientation }\end{array}$ \\
$\begin{array}{l}\text { Prevention / Palliative care } \\
\text { (factor 1) }\end{array}$ \\
\hline
\end{tabular}

\section{Discussion}

Using combinatorial optimization with the genetic algorithm we selected 30 out of 164 items which yielded the highest reliability. Using the factor analysis we recognised seven factors which belong to three of six in the EURACT Educational Agenda predefined competences of FM. Based on our analysis we found that students understand the competences of primary care management, person-centered care and comprehensive approach quite well, but they are not aware of specific decision making processes, the importance of balance between the needs of individual patients and the community, and the concept of holism.

All the items in the 30 -item questionnaire had positive connotation and expected answers were closer to 7 than 1 . However some students answered certain questions negatively. The reasons might be a lack of student motivation for completing the questionnaire, which was originally long and time consuming (12), or a lack of understanding of the discipline at the beginning of their FM clerkship. The participants had already had experience in hospital settings, but not necessarily experience in primary care. In hospital settings there are patients with severe illnesses, requiring a high intensity of care. There is inadequate opportunity during classroom learning to teach about care continuum, cost effectiveness, chronic disease management, family and patient perspectives and the impact of the social environment on illness (10).

Based on the sum of all the 30 items we found that generally the understanding of the discipline of FM in our sample of students was of an acceptable level. There were no gender differences in the perceived meaning of the discipline of FM. The clerkship in FM in the last year of their study is their first classroom learning in primary care (19), but with our results we confirmed that students generally obtain knowledge about primary health care from practical experience rather than from classroom learning (20).

Social justice, patient-centeredness, partnership, communication skills and empathy were factors recognised by the students that express the social role of family doctors. On the other hand, among the selected items there were no statements which belong to the competence "specific problem-solving skills", which cover the characteristics of the specific decision making process of family doctors and present a key characteristic of the family doctor as a medical expert.

Based on our analyses we could confirm the findings from the research about medical students' attitudes toward FM, that students value the social role of family medicine and family doctors more than their scientific value (21). We could add that students also recognise the importance of organisational and management skills of family doctors and recognise them as teachers in organisational and management skills. In a systematic review it was found that students recognised the need to develop leadership and 
management competences, since relatively little emphasis was placed on leadership and management in medical curricula (11).

Students did not recognise the important role of family doctors in incorporating the community in the management of patients. Hospital based learning was focused on biomedical knowledge necessary for treating acute ill patients, but long-term care of chronically ill patients should be patient-centered and should take the community into account as well as the individual patient (10).

Students also failed to recognise that the holistic approach to patients is one of the most important characteristics of FM. The concept of holism is multidimensional and might be misunderstood as complementary and alternative medicine (6). Specific teaching methods exist by which the holistic approach may be taught (watching movies, students' letter to patients) $(22,23)$. These methods were not used in previous education programs.

When comparing our results to the results of other studies, we were able to confirm that students understand the clinical competences of family doctors (8), but fail to understand some other competences of family doctors $(7,9-11)$. In a qualitative research synthesis about medical students' perception of and attitudes towards family medicine, it was found that most of the included studies describe factors which influence a career choice for family medicine (24). The correlation between understanding of the importance of primary care and the significance of the general practitioner's role in the healthcare system and career choice was detected (25). Positive perceptions regarding the possibility of having long term doctor-patient relationships and of treating complex disease patterns when working as a family physician, appears to be associated with the attractiveness of a career in family practice (26).

\section{Strengths and limitations}

The study was conducted on a representative sample of final-year medical students at the beginning of the FM clerkship. The questionnaire was developed specifically for the purpose of the study, adhering to the principles of qualitative research. The genetic algorithm is one of the best and most robust combinatorial optimisation methods. We could hardly expect a subset of items with much higher reliability than what we achieved.

Our study also has several limitations. We included only students of one of the two medical faculties in the country. Due to the slightly different curriculum of the Medical School in Maribor, their students could have a different understanding of the discipline at the beginning of their FM clerkship. Due to the cross-sectional design of the study we did not have to estimate some important aspects of reliability and validity, including test-retest reliability or responsiveness to changes.

Students answered the selected items with the whole range of possible answers (from 1 to 7 ), but the mean scores of the items were closer to the maximal value, since all the items had positive connotation, potentially leading to an "acquiescence" response style and possibly causing the result to be more positive regarding the understanding of family medicine. Some of the items included in the factor analysis had loading below the acceptable level and were not taken into account in the explanation of factors. On the other hand, based on the factor analysis, some of the factors consisted of items, which were contextually not suited to the other items in the factor and should be considered as non-classified items.

\section{Implications for practice}

Medical students should be taught the unrecognised competences of family doctors as part of the FM curriculum. As teachers 
we should adapt our curricula to address the competences which were not recognised by the students. Combining professional knowledge with a broad concept of humanistic personal development is a never-ending story and an important issue for medical schools in general, and some efforts have been already made at our Medical Faculty $(27,28)$.

In the seven-week clerkship of FM at Ljubljana faculty (29) we have to have a realistic view about the in depth understanding of some very complex concepts such as the holistic approach, which is sometimes difficult to understand even for experienced doctors. We are also aware that to understand specific problem-solving skills and community orientation, some more experience working in FM and close and long-term contact with patients is required $(10,30)$, but the clerkship should offer at least a basic understanding of these competences.

It would be interesting to check the students' understanding of the discipline after the implementation of our traditional curriculum of FM and after the adaptation based on our analyses, in order to see the influence of the adapted curriculum.

\section{Implication for research}

It would be interesting to know how experienced family doctors understand the discipline. There were some reports that even family doctors have a problem understanding the concept of holism. Family doctors' understanding of the discipline could be a template for adaptation of the EURACT definition of general practice /family medicine. It seems that the concept of holism is not a separate competence, but a general concept and covers the other five competences.

\section{Conclusion}

Final-year medical students at the beginning of their family medicine clerkship understand some of the dimensions of family med- icine well, but they are not aware of some important competences of family doctors. There is a need to teach students about specific problem-solving skills and the importance of balance between the health needs of an individual patient and the community.

Acknowledgments: The authors would like to thank the team of the Ljubljana family medicine department for their valuable input in the creation of ideas for the questionnaire and to the students who completed the questionnaire.

Authors' contributions: Conception and design: MPŠ, IŠ and BŠ; Acquisition, analysis, and interpretation of data: MPŠ, BŠ; Drafting the article: MPŠ, BŠ; Revising it critically for important intellectual content: IŠ, BŠ.

Conflict of interest: The authors declare that they have no conflict of interest.

\section{References}

1. Allen J, Gay B, Crebolder H, Heyrman J, Svab I, Ram P. The European definition of general practice / family medicine, revised version 2011. Barcelona: WONCA Europe; 2011.

2. Tandeter H, Carelli F, Timonen M, Javashvili G, Basak O, Wilm S, et al. A 'minimal core curriculum' for Family Medicine in undergraduate medical education: A European Delphi survey among EURACT representatives. Eur J Gen Pract. 2011;17:217-20.

3. Dixon AS, Lam CLK, Lam TP. Does a brief clerkship change Hong Kong medical students' ideas about general practice? Med Educ. 2000;34:339-47.

4. Rabadan FE, Hidalgo JLT. Changes in knowledge of and attitudes toward family medicine after completing a primary care course. Fam Med. 2010;42:35-40.

5. Heyrman J, editor. The EURACT Educational Agenda. Leuven: European Academy of Teachers in General Practice EURACT; 2005.

6. Strandberg EL, Ovhed I, Borgquist L, Wilhelmsson S. A perceived meaning of a (w)holistic view of general practitioners and district nurses in Swedish primary care: a qualitative study. BMC Fam practice. 2007;8:8. [cited 2013 May 1] Available from : http://www.biomedcentral.com/14712296/8/8.

7. Dent MM, Mathis M, Outland M, McKinley. Chronic disease management: Teaching medical 
students to incorporate community. Fam Med. 2010;42(10):736-40.

8. Hobbs J, Speers S, Herbert J, Nixon G, Poteet L, Hatch P. Clinical resources to reach components of a new family medicine clerkship curriculum. Fam Med. 2011;43(8):566-73.

9. Thimtsiou Z, Kerasidou O, Efstathiou N, Pahaharitou S, Hatzimouratidis K, Hatzichristou D. Medical students' attitudes toward patientcantered care: a longitudinal survey. Med Educ. 2007;41:146-53.

10. Pavanendran R, Vasanwala FF, Kamei RK, Hock LK, Lie DA. What medical students learn when they follow patient from hospital to community? A longitudinal qualitative study. Med Educ Online. 2012;17:18899. [cited 2013 May 1] Available from: http://www.ncbi.nlm.nih.gov/pmc/articles/ PMC3395028/.

11. Abbas MR, Quince TA, Wood DF, Benson JA. Attitudes of medical students to medical leadership and management: a systematic review to inform curriculum development. BMC Med Educ. 2011;11:91. [cited 2013 May 1] Available from: http://www.ncbi.nlm.nih.gov/pmc/articles/ PMC3247079/.

12. Petek Šter M, Švab I, Klemenc Ketiš Z, Kersnik J. Development and Validation of a Questionnaire for Evaluation of Students' Attitudes towards Family Medicine. Coll Antropol. (in press).

13. Maulik U. Medical image segmentation using genetic algorithms. IEEE Trans Inf Technol Biomed. 2009;13(2):166-73.

14. Vinterbo S, Ohno-Machado L. A genetic algorithm approach to multi-disorder diagnosis. Artif Intell Med. 2000;18(2):117-32.

15. Zheng B, Chang YH, Wang XH, Good WF, Gur D. Feature selection for computerized mass detection in digitized mammograms by using a genetic algorithm. Acad Radiol. 1999;6(6):327-32.

16. Mitchell M. An Introduction to Genetic Algorithms. Cambridge MA: MIT Press; 1996.

17. Whitley D. A genetic algorithm tutorial. Statistics and Computing. 1994;4(2):65-85.

18. Andrea G, Tettamanzi B, Tomassini M. Soft Computing: Integrating evolutionary, neural, and fuzzy systems. Berlin: Springer-Verlag; 2001.

19. Petek Šter M. Teaching Communication at Medical School in Ljubljana. Acta Med Acad. 2012;41:38-46.
20. Brown JB, French R, McCulloch A, Clendinning E. Primary health care models. Medical student's knowledge and perception. Can Fam Physician. 2012;58:e166-71.

21. Zurro AM, Villa JJ, Hijar AM, Tuduri XM, Puime AO, Coello PA, et al. Medical students attitudes toward family medicine in Spain: a state-wide analysis. BMC Fam Pract. 2012;13:47. [cited 2013 May 1] Available from: http://www.biomedcentral.com/1472-6920/12/81.

22. Klemenc Ketis Z, Kersnik J. Using movies to teach professionalism to medical students. BMC Medical Education. 2011;11:60. [cited 2013 May 1] Available from: http://www.biomedcentral. com/1472-6920/11/60.

23. Mrduljas-Djujic N, Pavlicevic I, Marusic A, Marusic M. Students' letters to patients as a part of education in family medicine. Acta Med Acad. 2012;41:52-8.

24. Olid AS, Zurro AM, Villa JJ, Hijar AM, TUdori XM, Puime AO, et al. Medical students' perceptions and attitudesabout family practice: a qualitative research synthesis. BMC Medical Education. 2012;12:81. [cited 2013 May 1] Available from: http://www.biomedcentral.com/1472-6920/12/81.

25. Dixon AS, Lam CLK, Lam TP. Does a brief clerkship change Hong Kong medical students' ideas about general practice? Med Educ. 2000;34:339-47.

26. Deutsch T, Hönigschmid P, Frese T, Sandholzer S. Early community-based family practice elective positively influences medical students' career considerations - a Pre-post-comparison. BMC Fam Pract. 2013;14:24. [cited 2013 May 1] Available from: http://www.biomedcentral.com/1471-2296/14/24.

27. Rus Makovec M. The reflective recognition of potentials of medical students and trainees: example workshops for tutors and mentors at the Medical faculty University of Ljubljana. Zdrav Var. 2012;51:268-77.

28. Švab I, Ribarič S, Plemenitaš A, Kopač I, Pirtošek Z. Sodobno medicinsko izobraževanje [in Slovene]. Zdrav Vestn. 2004;73:109-11.

29. Švab I. Petek Šter M. Long-term evaluation of undergraduate family medicine curriculum in Slovenia. Srb Arh Cel Lek. 2008;136:274-9.

30. Haidet P, Dains JE, Paterniti DA, Hechet L, Chang T, Tseng E, et al. Medical students attitudes toward the doctor-patient relationship. Med Educ. 2002;36:568-74. 